\title{
Zoonotic Infections Overview: A Nigerian Perspective
}

\author{
Faisal Muhammad (i] ${ }^{1,2,{ }^{*}}$ \\ ${ }^{1}$ Department of Public Health, Faculty of Allied Health Sciences, Daffodil International University, Dhaka, Bangladesh \\ ${ }^{2}$ Department of Social Work, School of Liberal Arts and Social Sciences, University of Information Technology and Sciences, Dhaka, Bangladesh \\ "Corresponding author: Department of Public Health, Daffodil International University (DIU) ,102 and 102/1 Shukrabad, Mirpur Road Dhanmondi, Dhaka, Bangladesh. Email: \\ fokkanya@yahoo.com
}

Received 2020 June 02; Revised 2020 June 28; Accepted 2020 July 08.

Keywords: Zoonotic, Infections, Public Health, Nigeria

\section{Dear Editor,}

Zoonoses are diseases that are naturally transmissible between the human and vertebrate animals, through agents such as bacterial, fungal, and viral agents. Research shows that over the past 10 years, about three-fourths of the new diseases that have affected human beings globally have been caused by pathogens originating from an animal or products of animal origin (1). One-fifth of the morbidity and mortality in the least developed countries are directly or indirectly associated with endemic zoonoses (2). Neglected zoonotic diseases (NZDs) are another serious issue among poor nations, including Nigeria. These diseases are called neglected because they mostly affect poor populations who normally live nearness to wild or domestic animals in areas where there is a scarcity of health and sufficient sanitary conditions. These diseases are also neglected because their burden is habitually concentrated in developing countries, in which the effort in the present day has focused on other diseases such as tuberculosis, malaria, HIV/AIDS, etc. (3). The transmission of these diseases can occur wherever humans live in both rural and urban settings. Contact with wildlife has increased nowadays due to the urbanization and the increased ecological changes that favor the development of some vectors of infection. Neglected zoonotic diseases take advantage of a double burden on the standard of life of people by ruining not only the quality of their health but also the life of livestock on which they laboriously rely for their survival.

According to the World Health Organization (WHO), eight diseases are identified as NZDs, including bovine tuberculosis, rabies, anthrax, echinococcosis, brucellosis, leishmaniasis, cysticercosis, and African human trypanosomiasis. Some NZDs such as brucellosis are considered important public health problems across the globe (4). Currently, many zoonotic infections are char- acterized to be endemic in Nigeria, such as Lassa fever, tuberculosis, yellow fever, trypanosomiasis, rabies, etc. There are also some sporadic cases of zoonotic infections like ascariasis, scabies, strongyloidiasis, etc. (5). In Nigeria, Lassa fever (LF) is an endemic disease that causes considerable illness and death. An outbreak of LF occurred just recently from January to May 2018. During this outbreak, a total of 1,893 cases were reported, leading to about 106 deaths among the laboratory-confirmed cases (6). An outbreak of yellow fever has been recorded in Nigeria long ago. The yellow fever outbreaks affected around 120,000 people between 1987 and 1996 across the Nigerian states. Recently in 2017, a new confirmed case of yellow fever was reported in Kwara State after 21 years of not reporting a confirmed case across the country (7). Bovine tuberculosis (BTB) is also endemic in Nigeria. However, BTB is still poorly controlled in Nigeria (8). A trypanosomiasis agglutination test was conducted among 474 human subjects, and about $9.6 \%$ of them were tested positive (9). A study among 149 suspected dog bite cases in Nigeria reported six confirmed cases of human rabies (10). Neglected zoonotic diseases have a dual burden because they can be devastating to both public and animal health. Targeting the animal reservoir to have optimal health may reduce the risk of NZDs for humans. Control and prevention measures of NZDs originating from animals should focus on interventions that target animal reservoirs combined with close collaborations and partnerships between veterinarians, physicians, and other stakeholders.

\section{Footnotes}

Authors' Contribution: The whole work was done by Faisal Muhammad. 
Conflict of Interests: The author has no conflict of interest.

\section{Funding/Support: None.}

\section{References}

1. Elelu N, Aiyedun JO, Mohammed IG, Oludairo OO, Odetokun IA, Mohammed KM, et al. Neglected zoonotic diseases in Nigeria: Role of the public health veterinarian. Pan Afr Med J. 2019;32:36. doi 10.11604/pamj.2019.32.36.15659. [PubMed: 31143341]. [PubMed Central: PMC6522207].

2. Rist CL, Arriola CS, Rubin C. Prioritizing zoonoses: A proposed one health tool for collaborative decision-making. PLoS One. 2014;9(10). e109986. doi: 10.1371/journal.pone.0109986. [PubMed: 25302612]. [PubMed Central: PMC4193859].

3. Mableson HE, Okello A, Picozzi K, Welburn SC. Neglected zoonotic diseases-the long and winding road to advocacy. PLoS Negl Trop Dis. 2014;8(6). e2800. doi: 10.1371/journal.pntd.0002800. [PubMed: 24901769]. [PubMed Central: PMC4046968].

4. World Health Organization. The control of neglected zoonotic diseases: $A$ route to poverty alleviation, report of a Joint WHO/DFID-AHP Meeting with the participation of FAO and OIE. Geneva: WHO; 2006
5. Coker AO, Isokpehi RD, Thomas BN, Fagbenro-Beyioku AF, Omilabu SA. Zoonotic infections in Nigeria: Overview from a medical perspective. Acta Trop. 2000;76(1):59-63. doi: 10.1016/s0001-706x(00)00091-7. [PubMed: 10913768].

6. Ilori EA, Furuse Y, Ipadeola OB, Dan-Nwafor CC, Abubakar A, WomiEteng $\mathrm{OE}$, et al. Epidemiologic and clinical features of lassa fever outbreak in Nigeria, January 1-May 6, 2018. Emerg Infect Dis. 2019;25(6):1066-74. doi: 10.3201/eid2506.181035. [PubMed: 31107222] [PubMed Central: PMC6537738].

7. Nwachukwu WE, Yusuff H, Nwangwu U, Okon A, Ogunniyi A, Imuetinyan-Clement J, et al. The response to re-emergence of yellow fever in Nigeria, 2017. Int J Infect Dis. 2020;92:189-96. doi: 10.1016/j.ijid.2019.12.034. [PubMed: 31935537].

8. Biu AA, Ijudai J. Prevalence and morphometric studies on porcine cysticercosis in Adamawa State, Nigeria. Sokoto J Vet Sci. 2012;10(1). doi: 10.4314/sokjvs.v10i1.6.

9. Nmorsi OPG, Isaac C, Igbinosa IB, Umukoro DO, Aitaikuru DP. Human African trypanosomiasis in endemic focus of Abraka, Nigeria. Asian Pac J Trop Biomed. 2010;3(6):448-50. doi: 10.1016/s1995-7645(10)60107-

10. Eke $\mathrm{CB}$, Omotowo IB, Ukoha OM, Ibe BC. Human rabies: still a neglected preventable disease in Nigeria. Niger $J$ Clin Pract. 2015;18(2):268-72. doi: 10.4103/1119-3077.151064. [PubMed: 25666005]. 